\title{
Os objetos da atualidade
}

\section{Cibele Barbará}

\begin{abstract}
Resumo
Este texto pretende contribuir para um conjunto de reflexões a respeito da relação do sujeito com os comumente chamados objetos da atualidade (gadgets) e, consequentemente, também pretende ampliar a leitura e as reflexões sobre o que faz esse mesmo sujeito enlaçar-se com o Outro. A aposta é que delimitar melhor o enlaçamento do sujeito com o Outro diz respeito não só à sua relação com este, mas também à sua relação com o objeto $a$.
\end{abstract}

\section{Palavras-chave:}

Discurso capitalista; Campo de gozo; Objetos; Atualidade.

\section{The objects of the present}

\begin{abstract}
This text intends to contribute to a set of reflections about the relation between the subject and the commonly called "objects of the present" (gadgets) and, consequently, it also intends to broaden the reading and the reflections on what makes this subject bond with the Other. The point is that the bonding of the subject with the Other concerns not only its relation to the Other, but also its relation to the object $a$.
\end{abstract}

\section{Keywords:}

Capitalist Discourse; Field of jouissance; Objects; Present.

\section{Os objetos de la actualidad}

\begin{abstract}
Resumen
Este texto tiene como objetivo contribuir a un conjunto de reflexiones sobre la relación del sujeto con los comúnmente llamados "objetos de la época actual" (gadgets) y, por tanto, también tiene la intención de ampliar la lectura y la reflexión sobre qué hace que este sujeto está enlazado con el Otro. El hecho es que la
\end{abstract}


conexión del sujeto con el Otro no solo concierne a su relación con el Otro, sino también a su relación con el objeto $a$.

\section{Palabras clave:}

Discurso capitalista; Campo del goce; Objetos; Actualidad.

\section{Les objets de nos jours}

\section{Résumé}

Ce texte vise à contribuer à un groupe de réflexions sur le rapport du sujet aux dits « objets de nos jours » (gadgets) et, par conséquent, entend également élargir la lecture et les réflexions sur ce qui fait que ce même sujet se lie avec l'Autre. Le pari, c'est que délimiter mieux le lien du sujet avec l'Autre relève non seulement de son rapport à celui-ci, mais aussi de son rapport à l'objet $a$.

\section{Mots clés :}

Discours capitaliste ; Champ de la jouissance ; Objets ; Actualité.

\section{Introdução}

Para acompanhar as relações de objeto e também dos laços na atualidade, três precisões fazem-se necessárias. Precisões simples, para aqueles que conhecem profundamente Lacan, mas nem sempre são tão óbvias para grande parte de quem o estuda. Nossa hipótese é de que, sem essas três precisões concomitantes descritas adiante, nós, psicanalistas, podemos cair em certo engodo em nossas experiências clínicas: tornarmo-nos alarmistas e/ou pessimistas em relação aos inúmeros objetos e serviços científico-tecnológicos ofertados pelo capitalismo. E, consequentemente, esquecermos o que está na causalidade do ser falante.

A primeira precisão é que as relações dos sujeitos com esses objetos da atualidade funcionam da mesma maneira que com qualquer outro objeto mundano: o falo como objeto ou mesmo como objeto mais-de-gozar. Não sem a participação dos sujeitos e da lógica pulsional em que estes se deixam capturar. Por isso, por estarem atentos, os analistas sabem que esses objetos não são objetos que funcionam como causa, mas, sim, são objetos da ordem da determinação.

Nesse sentido, esta é a segunda precisão: parece necessário diferenciar esses objetos cedíveis/parciais do objeto causa de desejo. Nenhum sujeito é consumido ou consome realmente um objeto, porque o lastro do sujeito é sua causa de desejo. Por isso, por mais homogeneizantes que sejam esses objetos ofertados, não pode- 
mos negar que há sempre a participação do sujeito em suas escolhas e no modo como se oferta a eles. Um analista conta com o vazio do desejo em causa.

A terceira precisão, simultânea às outras citadas, é a importância da função intermediária do Outro na relação do sujeito com os objetos. Como aquele que faz intermédio, como estrutura de linguagem. Aquele que é um lugar, não só de perda (perda inaugural civilizatória), mas de produção de objeto $a$, de captura de gozo parcial. Esse Outro, estruturalmente incompleto, que permite intervenção no campo do significante (Lacan, 1969/1970/1992). Algo bem mais amplo, como ele diz, que vai bem mais longe do que as enunciações efetivas. Suspeitamos que, para alcançar algo sobre os problemas da atualidade, é preciso questionar simultaneamente como esse vazio comparece e como o Outro da linguagem é evocado, que tipo de laço é estabelecido. Neste texto, de forma modesta, a pretensão é abordar como essas precisões podem dar início a uma pesquisa e preparar-nos para apreender melhor as relações estabelecidas na atualidade, especialmente com o discurso capitalista.

\section{“(...) desejar o Outro, o A maiúsculo, nunca é senão desejar $a .^{\text {"1 }}$}

Uma das fórmulas que Lacan não deixa de repetir em O Seminário, livro 10 é a de "Que a angústia não é desprovida de objeto" (Lacan, 1962-1963/2005). E, a partir dessa afirmação, podemos acompanhar os desenvolvimentos de Lacan sobre o objeto $a$ e a especificidade desse objeto que se apresenta na angústia. Aliás, essa afirmação não deixará de ser repetida por ele, mesmo em seus seminários mais avançados. Isso porque o objeto $a$ é condição para todo gozo e está no centro do nó borromeano, tema tratado por Lacan em seus últimos seminários (Soler, 2000-2001/2012a, p. 53).

Ao afirmar que a angústia não é sem objeto, ele inverte a noção de objeto postulada por Freud, presente, por exemplo, em Inibição, sintoma e angústia (Freud, S., 1992). Nesse texto, no caso do pequeno Hans, a angústia ganha um significante no mundo, perdendo seu caráter difuso, vinculando-se a uma representação específica: cavalo (Vieira, 2001). Aqui, estamos no nível do significante com esse “objeto mundano". Porém, não é a esse objeto que Lacan se refere quando fala sobre o objeto $a$. É possível encontrar nesse seminário certa reconsideração sobre como devemos entender o que é um objeto para a psicanálise, de tal modo a inverter as colocações freudianas, afirmando, de tal maneira, que a angústia não é desprovida de objeto, mas que o medo, sim, é desprovido de objeto (Lacan, 1962-1963/2005).

Essa discussão sobre o que é um objeto para a psicanálise parece tão importante que Lacan chega a afirmar que facilmente poderia sugerir que o objeto $a$ assume

1 Esse subtítulo é retirado de uma citação do Seminário, livro 10 (Lacan, 1962-1963/2005). 
a função de metáfora do sujeito do gozo, porém isso só poderia acontecer se o $a$ fosse assimilável a um significante. Ao contrário disso, o objeto a presentifica-se na esfera do significante como falta, como aquilo que foi perdido, porque o objeto $a$ resiste a qualquer significantização (Lacan, 1962-1963/2005).

É a partir do quadro desenhado (Lacan, 1962-1963/2005, p. 192) por Lacan em algumas aulas desse seminário que podemos tentar apreender melhor algo do enlaçamento com o Outro e do papel do objeto $a$ nisso.

Figura 1. Quadro proposto por Lacan.

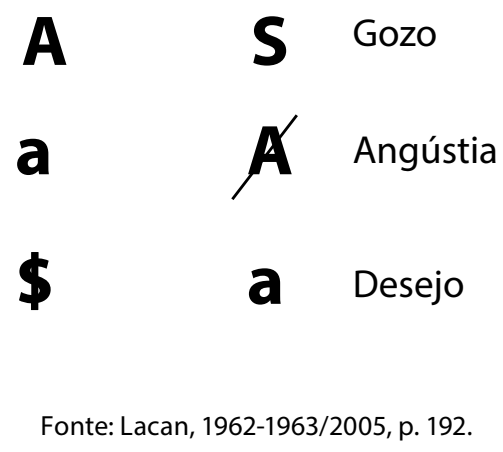

Logo antes do quadro, Lacan (1962-1963/2005, p. 192) lança: “(..) é por intermédio do Outro que o sujeito deve se realizar”. Aqui, já podemos entender o Outro como mediador, não como condição exclusiva. Devemos observar que, nesse mesmo quadro, a angústia é colocada por Lacan em uma função mediana; está entre o gozo e o desejo. Ele ressalta: "É nesta disposição em patamares que avançarei hoje, para lhes mostrar a função - não mediadora, mas mediana - da angústia entre o gozo e o desejo" (Lacan, 1962-1963/2005, p. 192). Vejam que ele diz mediana, e não mediadora, como na frase sobre o Outro. Não é a mesma coisa. Mediano diz respeito a algo que está colocado no meio, entre dois extremos. E intermédio diz respeito àquele que promove acordo entre partes em conflito, estabelecendo um diálogo. Disso, já podemos começar a extrair algumas coisas.

Lacan afirma, em O Seminário, livro 10: “Que o gozo não conhece o Outro senão através desse resto $a$ ” (Lacan, 1962-1963/2005, p. 192). Isso não é o mesmo que dizer que o falante não conhece o Outro se não for através desse resto $a$ ? $\mathrm{Ou}$ mesmo o que faz do outro um grande Outro é justamente a participação do objeto $a$ ? Ao supor "o seu objeto $a$ " em um pequeno outro, não é aí que o Outro surge? Surge como mediador da realização do sujeito? Ele é muito claro em dizer que 
o que um falante busca não é o gozo, mas o Outro. No entanto, o que significa buscar o Outro? "O que é buscado é a petição do Outro. (...) o $a$, para o homem, é o acesso ao Outro, a tentativa de acesso ao Outro. Ele insiste, desejar $a$ é desejar o Outro" (Soler, 2006-2007/2012b, p. 98). Vejam que estamos no campo do desejo, da realização do sujeito.

Especificamente, o que se busca no outro é um pedido para daí tentar sacar uma resposta: "Mas é ao querer fazer esse gozo entrar no lugar do Outro, como lugar do significante, que o sujeito se precipita, antecipa-se como desejante" (Lacan, 1962-1963/2005, p. 194). O a é tudo que resta do sujeito mítico, e é isso que fará sua entrada na fantasia fundamental. O desejo aiza o outro (Lacan, 1962-1963/2005). Buscamos o outro, mas só podemos fazer isso se este for "aizado", ou seja, se no outro for suposto o $a$ : “(...) o desejo aiza o outro, busca o outro, mas o aiza, não pode fazer de outra forma senão aizá-lo” (Soler, 2006-2007/2012b, p. 100).

Essa parece ser uma das inversões que Lacan traz quando relembra a cerimônia do chofar, ao dizer que a emissão desse som é que faz Deus existir. Chofar para fazer presença diante da possibilidade de ficar desamparado ou à deriva: “(chofar) É um objeto, e que me servirá de eixo para substantivar diante de vocês o que entendo pela função do $a$ nesse estágio, o último, no qual ele nos permite revelar a função de sustentação que liga o desejo à angústia no que é seu derradeiro nó" (Lacan, 1962-1963/2005, p. 268). Precisamente, não se trata de tremer diante do Pai, mas de chofar para fazer existir o Pai, fazer a presença de Deus. Só aí, então, poder supor que o que ele pede é que tremamos diante de sua presença: "O chofar é, portanto, um desejo que invoca o objeto no Outro. Que objeto? O objeto que apela à voz de Deus, aqui o Outro" (Soler, 2006-2007/2012b, p. 122). A demanda suposta do Outro assume a função de objeto (Lacan, 1960/1998). Esse jogo parece essencial para a construção da demanda e para dela extrair o objeto $a$. E será isso que invocará o Outro ou mesmo se enlaçará com este, mediador da realização do desejo.

Isso faz retomar a fórmula de Lacan (1962-1963/2005): a angústia não é sem objeto. Não é sem objeto, não tira o Outro da jogada, porém dá a este último um papel mediador, como destacou Lacan, e não um papel mediano na entrada do falante na fantasia. É o que comenta Soler sobre essa fórmula de Lacan em que se faz o exercício de interrogá-la, extraindo desta outras fórmulas excluídas: "Creio que a primeira que é afastada, quando ele diz 'a angústia não é sem objeto', é 'a angústia não é sem o Outro'. No entanto, observem que não seria uma aberração dizer: 'a angústia não é sem o Outro'. Porém, ele não disse! Ele disse não é sem objeto" (Soler, 2000-2001/2012a, p. 24). A partir dessa lógica excludente, não podemos entender que essa relação com o Outro não é tão automática assim e depende do tipo de relação que se estabelece do falante com o objeto $a$ ? Depende do lugar e da operância do objeto $a$ : 
Proporemos também algumas outras (formas), que deduzem do nosso quadrinho em que se mostra que o $a$ como tal, e nada mais, é o acesso não ao gozo, mas ao Outro. Isso é tudo o que resta dele a partir do momento em que o sujeito quer fazer sua entrada nesse Outro. (...) Portanto, desejar o Outro, o A maiúsculo, nunca é senão desejar a. (Lacan, 1962-1963/2005, p. 198)

É preciso que o objeto $a$ entre na jogada de certa forma, para fazer o Outro desejável, aizado. Talvez seja o mesmo que dizer que a linguagem precisa estar "aizada", “idealizada” para que o sujeito nela deseje realizar-se. Uma espécie de truque, de artifício. É possível perceber como o Outro comparece como um lugar, como uma estrutura necessária para o sujeito realizar-se.

Vejam, não é o vazio do enigma da resposta do Outro que angustia. A angústia apresenta-se em um momento de determinação, pela iminência de uma resposta, na iminência de apreender-se como objeto. Ela designa o mais profundo, o objeto derradeiro, a Coisa (Lacan, 1962-1963/2005). Ele explica que é nesse primeiro momento da angústia, encontro do sujeito mítico com a linguagem, que um corte é realizado. Mas como seria essa operação?

\section{Operação - extração: objeto separtido e objeto cedido}

Um dos exemplos que Lacan usa para ilustrar essa operação é o desmame. Ele ressalta que não se trata de um seio que fará falta ao pequeno sujeito, mas trata-se, sim, de um recorte que funda e separa ao mesmo tempo seio e bebê. Seio que é percebido a posteriori pelo bebê como uma parte separtida, cortada dele mesmo, e não da mãe: “(...) durante a amamentação, o seio faz parte do indivíduo alimentado, encontra-se apenas chapado na mãe, como eu lhes disse numa expressão afigurada" (Lacan, 1962-1963/2005, p. 340). A separtição é que funda e recorta ao mesmo tempo um objeto ilógico até então. Como se uma música rompesse o espaço cantarolando e/ou como se um espaço rompesse uma música silenciando. Está feito um corte em um suposto chapado inerte que não volta mais.

Esse encontro com a linguagem pressupõe uma primeira falta e a queda de um objeto, objeto separtido: objeto singular, sem nome, imagem ou significante. E é esse objeto, objeto $a$, caído, cortado pela operação da linguagem, que funda $\$$ e A barrado. É importante observar que funda o Outro barrado, e não o Outro não barrado. A separtição é a queda daquilo que do ser não passa ao significante, destacando-se do falante. Essa operação acontece no nível do Real ou, como Soler destaca, no nível do corpo: “(...) separtição do corpo, entre um corpo esvaziado de gozo e este objeto que permaneceu ligado ao gozo" (Soler, 2006-2007/2012b, p. 147). Esse primeiro corte passa pela unidade viva da criança e no Outro, que seria 
o corpo da mãe.

Pode parecer óbvio incialmente, mas é importante observar que, nessa operação de separtição, que funda \$ e Outro barrado, o desejo está no lado de onde o objeto é subtraído, nesse caso no lado do sujeito, e a angústia estaria no lado do Outro, representada por certa insatisfação ou mesmo esgotamento. Isso afirma o lugar do desejo como causa e liga a angústia ao esgotamento, à insatisfação, e não ao desejo do Outro: "De um lado temos a falta do desejo e do outro a falta da satisfação” (Soler, 2006-2007/2012b, p. 122).

Figura 2.

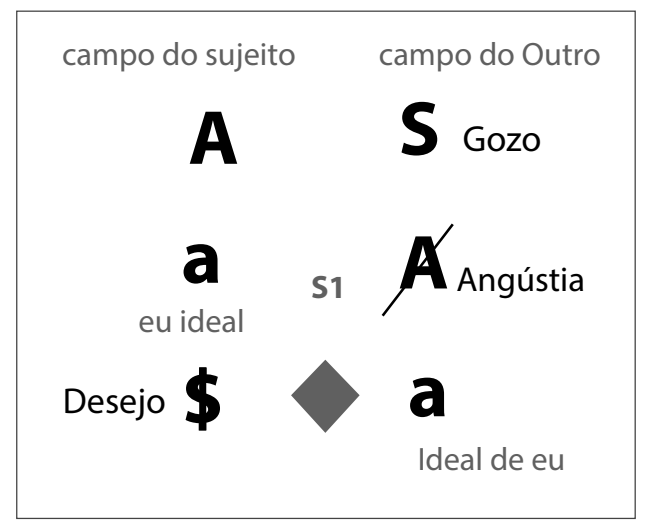

\author{
O ponto de angústia está \\ do lado do Outro. \\ Função mediana da angústia, \\ entre gozo e o desejo. \\ a como resto e como garantia \\ de alteridade do Outro. \\ a é um objeto separado, não do \\ organismo da mãe, mas do \\ organismo da criança. \\ O desejo está do lado em que o \\ objeto é subtraído, a angústia \\ está do lado do Outro.
}

Fonte: Inspirado no quadro de Lacan, 1962-1963/2005, p. 192.

Esse esgotamento, segundo a leitura de Soler, não é do leite, mas da voz: "É a voz que pode faltar" (Soler, 2006-2007/2012b, p. 124). Se a voz se esgota, a possibilidade de desamparo é imitente. Diante da ameaça do desamparo, de derivar infinitamente através da fenda do Outro, o falante pode chofar e, daí, extrair um objeto que supõe satisfazer o Outro: "O chofar é, portanto, um desejo que invoca o objeto no Outro. Que objeto? O objeto que apela à voz de Deus, aqui o Outro" (Soler, 2006-2007/2012b, p. 122).

E aqui, neste momento lógico, começamos a situar-nos no que Lacan chamou de objeto cedido. Diante dessa insatisfação, é preciso fazer aparecer um objeto que supostamente tampone a hiância aberta pela barra do Outro. Diante da insatisfação do outro, uma parte é cedida para salvar o resto. Esse objeto cedido tem como função veicular primitivamente algo da identidade do corpo antecedendo ao próprio corpo quanto à constituição do sujeito (Lacan, 1962-1963/2005). Trata-se de uma operação da linguagem entre o sujeito e o Outro, em que esse objeto, por 
meio dos significantes, representa o sujeito. Ele surge exatamente para responder à angústia situada no lado do Outro. Como sublinha Soler, ele não é efeito da angústia, ele é resposta: “O objeto cedido vem depois, são objetos plurais” (Soler, 2006-2007/2012b, p. 149). Esses objetos cedíveis, agora podemos falar no plural, representam o sujeito em alguma forma de gozo. Os objetos cedíveis aqui, para aproveitar o que já comentamos anteriormente, são os objetos pulsionais que representam o vazio do objeto causa de desejo. É com a libra de carne, um pedaço de seu corpo, que o sujeito pagará sua dívida, diz Lacan (1962-1963/2005), tomando como exemplo o Mercador de Veneza, de Shakespeare. Cede-se uma libra para salvar o restante. É aí que parece entrar a operância do objeto $a$.

Diante da suposta insatisfação do Outro (resultado do chofar) e de toda a demanda que lhe atribuo, ofereço um pedaço de corpo para salvar o restante, o objeto causa de desejo. Ofereço, cedo um pedaço de corpo, porque é isso que suponho que o Outro deseje, demonstrando que, no fundo, ser desejado não é ser desejado como sujeito, mas como corpo: "A metonímia da falta não diz que desejamos o corpo, ora, ele insiste muito, o desejo é sempre desejo de corpo. Ser desejado, é ser desejado como corpo, não como sujeito, portanto" (Soler, 2006-2007/2012b, p. 113).

A extimidade do objeto $a$ causa de desejo só pode ser apreendida através dos objetos cedíveis/parciais. Ceder-se como um objeto parcial ao Outro - porque, supostamente, assim o Outro demanda - é uma forma de fazer um entrelaçamento com o Outro. Oferecer-se como objeto cedível é uma forma que o sujeito encontrou para fazer do Outro um anteparo, um meio de realização. Os objetos pulsionais são os quatro suportes que constituem a causa de desejo: "Suportes e formas de predicar esse objeto impredicável que é o objeto $a$ ” (Gianesi, 2011). O sujeito oferece-se ao Outro como uma boca, um olho etc.

Gianesi (2011) explica que, em O seminário, livro 16: de um Outro ao outro, Lacan é novamente afirmativo, ao dizer que o objeto é um lugar de captura de gozo, através das quatro formas predicativas: voz, olhar, fezes e seio (Gianesi, 2011, p. 186). Essa é a forma de ceder-se ao Outro, oferecendo-se, pois supõe o objeto de demanda do Outro.

Aí está uma divisão fundamental do sujeito. De um lado, sua causa de desejo, seu lastro; e, de outro, seu laço com o Outro, com a civilização, com os discursos. Fazer a diferenciação entre o objeto causa de desejo e os objetos cedíveis/parciais é fundamental, pois, "caso fosse algo positivo, desejar seria consumir o objeto, esgotando[,] assim, tanto causa quanto efeito" (Garcia, 2015, p. 150). Se fosse assim, deveríamos ficar alarmados diante da relação dos sujeitos com os gadgets, por exemplo. Haveria consumação geral e real do sujeito pelos objetos e dos objetos pelo sujeito. Em outras palavras, a relação sexual seria possível.

O objeto causa de desejo, estrutural, como vazio fundamental, é importante, não só para pensar sobre o desejo, mas também sobre a pulsão na apreensão de um ob- 
jeto: “Ou seja, não se alude, na satisfação do gozo, a um objeto positivo, que dê conta de uma necessidade, tal como no consumo. Com o objeto da pulsão, não se trata de objeto, mas do vazio que ele produz para que a pulsão o contorne" (Garcia, 2015, p. 151). Como diz Lacan em O seminário, livro 11 (Lacan, 1964/1993), o objeto só é objeto a posteriori, no retorno à pulsão. O que interessa à pulsão é a possibilidade de contornar um objeto vazio: "É por ser objeto vazio, perdido, sem positividade, que a pulsão toma o a como essa espécie de alvo, onde o que interessa não é atingir nada, mas contorná-lo, tomar[,] a partir dali, seu impulso" (Garcia, 2015, p. 151).

Essa operação de construção da demanda é essencial para a extração do objeto $a$; e o objeto $a$ é imprescindível para realizar um tipo de enlaçamento com o Outro que possibilite a entrada na avenida no desejo. De outro modo, é essa via do desejo que inscreve o Outro como lugar e possibilita movimento em direção ao objeto $a$ causa de desejo (Soler, 2000-2001/2012a). É nesse sentido que o desejo aiza o Outro.

Agora, o que acontece quando o objeto $a$, em vez de comparecer como um vazio "potencial", aparece determinado? Determinado, precipitado, antes mesmo que o próprio sujeito tenha tido a experiência de sonhá-lo?

\section{O laço com o Outro e o discurso capitalista}

Até aqui, pudemos perceber que o objeto $a$ é um conceito fundamental, que permite um alcance além dos objetos pulsionais freudianos. Resto da inscrição no campo da linguagem, é ele que abre espaço para investigações dos problemas relativos ao real. Sua relação com a linguagem e, especialmente, os limites que tem com ela permitem outras compreensões sobre os discursos. Considerar o objeto $a$ não só ilumina os limites entre a linguagem e o real, mas indica como a estrutura de linguagem do inconsciente inclui o real como causa: “(..) ou seja, que o real enquanto limite que se impõe à linguagem possui uma função naquilo que a própria linguagem estrutura" (Faria, 2019, p. 21). Aprofundar nossos estudos sobre o objeto $a$, bem como diferenciar objeto $a$ causa de desejo de objeto $a$ mais-de-gozar, por exemplo, pode ajudar-nos a alcançar, mesmo que pelas bordas, as especificidades de nosso fazer e também das formas de sofrimento da atualidade. Não parece à toa que o objeto a causa de desejo esteja presente apenas no discurso do analista, e que o objeto $a$, em sua incidência mais-de-gozar, nos outros discursos.

Para nós, psicanalistas, essa estrutura linguageira, formalizada por Lacan como discursos sociais (formas de laço), é, então, essencial. A existência do inconsciente e mesmo a do sujeito dependem dos discursos e de seus elementos $\left(\mathrm{S}_{1}, \mathrm{~S}_{2}\right.$, \$ e $\left.a\right)$. Nos discursos, do mestre, inclusive, está demarcado o campo do sujeito e o campo do Outro. Não há inconsciente se o discurso do Outro não estiver presente para o sujeito. Para que uma análise possa acontecer, é preciso a presença do inconsciente, e, para que o inconsciente possa comparecer, é preciso o laço com o Outro. 
No discurs o capitalista, não se trata, como explica Soler (2005), de um laço sem a linguagem, mas, sim, com a função da linguagem reduzida a um instrumento de mercado, um laço que não se realiza entre indivíduos:

Sem dúvida, é um laço, mas um laço pouco social, pois não se realiza entre indivíduos. Isso deixa cada sujeito sozinho com suas buscas, buscas estas pouco sublimatórias. Nesse sentido, pode-se dizer - mas é preciso refletir se é possível sustentá-lo - que é uma ordem sem Outro, sem grande Outro. Certamente há o Outro da linguagem, mas a função da linguagem nesse discurso se reduz a um instrumento de mercado, um aparelho, porém, que tanto produz quanto faz consumir, pois é preciso incentivar o apetite. Por isso, digo sem Outro, mas no sentido do Outro barrado. (Soler, 2005, p. 15)

O Outro barrado é quem abre espaço para um campo em que nele o laço social torna-se possível. Não sem o objeto, mas contando com uma cadeia significante na qual os pares escritos possam estabelecer-se nos patamares superiores dos quatro discursos de Lacan: o mestre e o escravo, a ciência e seu objeto, a histeria e o mestre, o analista e o analisante (Soler, 2013).

Porém, nem sempre essas relações entre pares estão presentes, ou nem sempre, explica Soler, as conjunturas da angústia apresentam-se relacionadas com o Outro (valorado como maldoso, perverso, admirável etc. ${ }^{2}$ ) e/ou encarnada na figura de um Outro: “(...) a angústia pode muito bem passar do sujeito ao sujeito, do sujeito a seu objeto” (Soler, 2000-2001/2012a, p. 45). Essa relação possível do sujeito a seu objeto parece importante para nos fazer começar a entender um pouco mais o que é uma função de linguagem reduzida a um instrumento de mercado.

Sem levarmos em conta essa possibilidade de relação solitária do sujeito com os objetos, não poderemos entender ou tentar vislumbrar as relações estabelecidas com o objeto no discurso capitalista formalizado por Lacan. Nesse matema, o impossível, representado por Lacan pelas barras entre o lado do agente e o lado do Outro, não está estabelecido, e isso gera consequências importantes em seu funcionamento e nas relações dos sujeitos com os objetos.

Se fizermos uma comparação entre o discurso capitalista e o discurso do mestre, é o impossível estabelecido no patamar superior $\left(S_{1}-S_{2}\right)$ que gera hiância entre o gozo que se pretende/almeja alcançar e a verdade singular de cada sujeito. Ou seja, é a impossibilidade de colusão entre $S_{1}-S_{2}$ que faz com que os produtos

2 Aqui, é preciso esclarecer que essa orientação é sustentada pelas leituras psicanalíticas, que, como qualquer outro discurso teórico, tem seus limites. Outros campos do conhecimento, bem como teorias sociais, têm excelentes discussões a respeito do assunto. 
pulsionais, estabelecidos a posteriori, não sejam equivalentes àqueles idealizados, àqueles que nos faltam ou nos causam. (Lembrando que o objeto da pulsão é contingente, sem ser totalmente indeterminado.) A questão é que justamente esse impossível, esse limite delineia lugares e permite diferenças em um discurso. No discurso capitalista, não há barreiras, não há diferença entre os lugares (essenciais e estruturais no funcionamento de um discurso). Temos, assim, um discurso fechado, sem aberturas. Isso está formalizado por Lacan através das setas:

Figura 3. Quadro dos discursos.

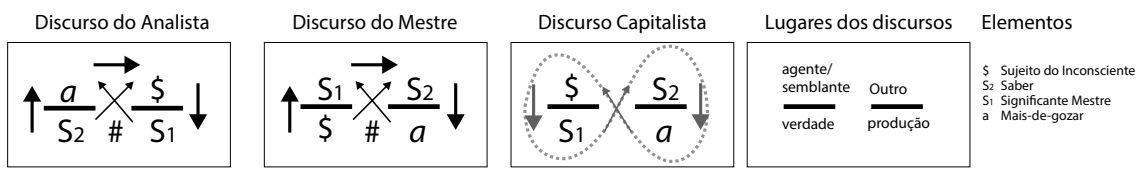

Fonte: Inspirado nos discursos de Lacan, 1969-1970/1992, p. 51.

São os lugares que estruturam a possibilidade de dissimetria, ao mesmo tempo que são as dissimetrias que fundam os lugares. No discurso capitalista, eles são equivalentes! Vejam, são os lugares e suas dissimetrias que possibilitam a atribuição de valor aos elementos que ali são ocupados. São esses limites que instituem os atores dos discursos. Nos quatro discursos estabelecidos por Lacan, o lugar da produção é o que aparentemente comanda e faz retroativamente a roda girar (mais-valia). Isso talvez seja o mais importante, não sem a participação do elemento que está no lugar de agente na nomeação de sua cadeia significante: "(nos quatro discursos) temos um sujeito que nomeia a cadeia, a cadeia que nomeia a produção dos objetos, e objetos que comandam o sujeito" (Soler, 2005-2006/2007, p. 138, tradução nossa).

No discurso capitalista, em razão de seu circuito fechado e da indistinção de lugares, não há dominantes. Isso abre precedentes para que os sujeitos não só explorem os objetos produzidos por esse discurso, mas também sejam explorados pelos objetos, ou seja, que sofram o efeito de suas próprias produções - já não são mais explorados pelo mestre, mas pelos objetos, dirá Lacan. Não podemos esquecer que o discurso capitalista é aquele que promete novos e instantâneos gozos, novas necessidades $\mathrm{E}$ faz isso porque faz sobressair o valor de troca sobre o valor de uso, impossibilitando este último de realizar-se parcialmente: "Só oferece o laço de cada um aos seus mais-de-gozar” (Soler, 2013). 
Talvez o ponto crítico não seja especificamente a mútua exploração do sujeito para com seus objetos, mas a quebra desse paradoxo implícito da nomeação da cadeia. Mesmo que, aparentemente, os objetos — os produtos dos discursos - comandem a posteriori o sujeito, a distinção dos lugares e mesmo a circulação deles permitem certo movimento e certa ação nomeadora da cadeia. Ou seja, mesmo que o objeto $a$, aqui em sua versão de mais-de-gozar, seja um empuxo à civilização (e, consequentemente, a seu mal-estar), temos aqui a possibilidade de circulação entre os discursos, bem como a participação, nem sempre tão evidente, do lugar do agente.

Como fica isso no discurso capitalista, se os lugares estão homogeneizados? Isso não abre precedentes para pensarmos que, nesse discurso, os objetos produzidos, predeterminados, antecipem-se ao exercício do sujeito na nomeação da cadeia. Não haveria aqui um excesso de determinação? As setas desse discurso demonstram isso. Sem o impossível colocado entre os dois lados, o que temos é a prevalência do objeto para com o sujeito. Uma antecipação do objeto à divisão do sujeito.

Não há, como salienta Soler (2005-2006/2007), no discurso capitalista, nenhum parceiro, como nos outros discursos, que faça algum contraponto. As relações dos sujeitos com seus objetos é muito singular, visto que têm uma relação muito específica com aquilo que nomeou desejo do Outro. A questão é que, no discurso capitalista, os objetos são universais para todos. São globais e acabam fechando os espaços para o exercício da singularidade, da experimentação. Os sujeitos entram com uma participação muito menos ativa e criativa. Claro que não há como conceber, especialmente porque contamos com o objeto causa de desejo, que o sujeito participante desse discurso seja apenas uma vítima. Sabemos que não é sem sua escolha, afinal há uma identificação com o objeto de consumo. Mas, como em qualquer discurso, seu funcionamento não é sem consequência.

Nos quatro discursos, as relações com os objetos são intermediadas pelo Outro, são produtos dessa relação e abrem espaço/tempo para funcionar todo o jogo da fantasia. Fantasia, produto da relação do sujeito e do Outro. Aqui, a função da linguagem não comparece reduzida a um instrumento de mercado. Ao contrário, ela tem potencial, potencial poético, criativo. Aqui, há possibilidade de desejo, mas também de algum gozo. Tanto que, de modo diferente do que, aparentemente, concluímos nas relações excessivas dos sujeitos com seus objetos na atualidade, como nas drogadições, não se trata de excesso de gozo, mas de falta de gozo. Lembrando que o objeto $a$ é condição para todo gozo:

A produção extensiva, insaciável, é produção da falta do Outro. A produção insaciável do objeto mais-de-gozar é produção insaciável da falta de gozo. (...) É isso que concerne à nossa época, porque, como sabem, há algumas vozes que apareceram na psicanálise para dizer que agora os su- 
jeitos são sujeitos adictos do gozo. Essa é uma ideia totalmente contrária à tese de Lacan, porque se esquece que os adictos ao mais-de-gozar gadgets são adictos à falta de gozo e, assim, com isso entendemos a grande queixa atual dos sujeitos. (Soler, 2005-2006/2007, p. 142, tradução nossa)

Vejam que o que parece problemático nessas situações é que há um empobrecimento da vida psíquica, não pela crise em si, mas pelo que é feito dela. Já que, nessas situações, em vez de oferecer um lugar de saber de trabalho, de enlaçamento, que aproxime o sujeito de seus significantes fundamentais, o que esse discurso oferece são formas prontas de sofrimento e objetos para consumo homogeneizados:

O trabalho de singularização do sintoma, ou melhor[,] do sinthome, é poupado pela identificação por outras formas de mal-estar e pela proliferação de sintomas transitórios. O retraimento evolui para a narrativa do consumo ou para a descrição de experiências. (Dunker, 2002, p. 153)

A possibilidade de viver experiências e não de descrevê-las, a possibilidade de construção de um saber, de criação fica cada mais vez mais distante e precária. Lembremos que o Saber $\left(\mathrm{S}_{2}\right)$ está no lugar da verdade, como causa, no discurso do analista.

\section{Referências bibliográficas}

Dunker, C. I. L. (2002). Cálculo neurótico do gozo (1a ed.). São Paulo: Escuta.

Faria, M. R. (2019). Real, simbólico e imaginário no ensino de Jacques Lacan (1a ed.). São Paulo: Toro. (Trabalho original publicado em 2010)

Freud, S. (1992). Inhibición, sintoma y angustia. In Obras Completas Sigmund Freud (v. XX, pp. 71-164). Buenos Aires, Argentina: Amorrortu. (Trabalho original publicado em 1926[1925]).

Garcia, L. F. B. (2015). Despertar do real: a inversão do objeto a. (Dissertação de mestrado). Faculdade de Filosofia, Letras e Ciências Humanas, Universidade de São Paulo, São Paulo. Recuperado em 19 março, 2019, de www.teses.usp.br

Gianesi, A. P. (2011). Causalidade e desencadeamento na clínica psicanalítica (1a ed.). São Paulo: Annablume.

Lacan, J. (1992). O seminário, livro 17: o avesso da psicanálise. Rio de Janeiro: Jorge Zahar. (Trabalho original publicado em 1969-1970)

Lacan, J. (1993). O seminário, livro 11: Os quatro conceitos fundamentais da Psicanálise $(2 \mathrm{ed})$. Rio de Janeiro: Zahar. (Trabalho original publicado em 1964).

Lacan, J. (1998). Subversão do sujeito e dialética do desejo no inconsciente freudiano. In J. Lacan. Escritos (pp. 807-842) (Vera Ribeiro, Trad.). Rio de Janeiro: Jorge Zahar. (Trabalho original publicado em 1960) 
Lacan, J. (2005). O seminário, livro 10: a angústia. (Vera Ribeiro, Trad.). Rio de Janeiro: Jorge Zahar. (Trabalho original publicado em 1962-1963)

Soler, C. (2005). Mudança na amarração da angústia. Stylus: Revista de Psicanálise, Rio de Janeiro, (11), 13-25.

Soler, C. (2007). Los discursos de Lacan: Seminario del Colegio de Psicoanalisis de Madrid. Esta obra recoge las sesiones del seminario de Psicoanalisis de Madrid, celebrado en Madrid. Madri: Campillo Nevado S.A. (Trabalho original publicado em 2005-2006)

Soler, C. (2012a). Declinações da angústia. São Paulo: Escuta. (Trabalho original publicado em 2000-2001)

Soler, C. (2012b). Seminário de leitura de texto ano 2006-2007: seminário A angústia, de Jacques Lacan. São Paulo: Escuta. (Trabalho original publicado em 2006-2007)

Soler, C. (2013). A oferta, a demanda e... a resposta. Stylus: Revista de Psicanálise, Rio de Janeiro, (26), 15-28. Recuperado em 19 março, 2019, http://pepsic. bvsalud.org/scielo.php?script=sci_arttext\&pid=S1676-157X2013000100002\& lng $=\mathrm{pt} \& \mathrm{t} \operatorname{lng}=\mathrm{pt}$

Soler, C. (2016). O Um totalmente só e seus laços. (Vera Pollo, Trad.). Stylus: Re-

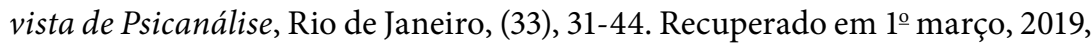
http://pepsic.bvsalud.org/scielo.php?script=sci_arttext\&pid=S1676-157X2016 $000200003 \& \operatorname{lng}=\mathrm{pt} \& \operatorname{lng}=\mathrm{pt}$

Vieira, M. A. (2001). A ética da paixão: uma teoria psicanalítica do afeto. Rio de Janeiro: Jorge Zahar. Recuperado em $1^{\circ}$ março, 2019, http://lacanempdf.blogspot.com/2017/02/a-etica-da-paixao-um-estudo.html

Recebido: 14/10/2019

Aprovado: $12 / 02 / 2020$ 